\title{
Patient with toxoplasmosis and glucose-6-phosphate dehydrogenase deficiency: a case report
}

\author{
Altacílio A Nunes
}

Address: Department of Social Medicine, University of Sao Paulo, Avenida Bandeirantes, 3900 - Monte Alegre, 14.048-900 - Ribeirao Preto SP, Brazil

Email: altacilio@fmrp.usp.br

Received: 28 October 2008 Accepted: 30 July 2009 Published: 6 August 2009

Cases Journal 2009, 2:8826 doi: 10.4076/1757-1626-2-8826

This article is available from: http://casesjournal.com/casesjournal/article/view/8826

(C) 2009 Nunes; licensee Cases Network Ltd.

This is an Open Access article distributed under the terms of the Creative Commons Attribution License (http://creativecommons.org/licenses/by/3.0), which permits unrestricted use, distribution, and reproduction in any medium, provided the original work is properly cited.

\begin{abstract}
Introduction: Toxoplasmosis, a zoonotic protozoal disease caused by toxoplasma gondii, is prevalent throughout the world, affecting a large proportion of persons who usually have no symptoms. Glucose 6 phosphate dehydrogenase deficiency, an X-linked inherited disorder, is present in over 400 million people world wide. It is more common in tropical and subtropical countries and is one of the important causes of hemolytic anemia.

Case presentation: This case report relates the occurrence of the two diseases simultaneously in a child of five years old.

Conclusion: Patients with glucose-6-phosphate dehydrogenase deficiency are more susceptible to toxoplasmosis and this case report, reinforce the findings of this propensity and alert us for such possibility, what it is important, therefore, the treatment of toxoplasmosis can cause serious hemolysis in these patients.
\end{abstract}

\section{Introduction}

Toxoplasmosis is a disease generated by toxoplasma gondii, a protozoan parasite that infects up to a third of the world's population. Infection is mainly acquired by ingestion of food or water that is contaminated with oocysts shed by cats or by eating undercooked or raw meat containing tissue cysts. Primary infection is usually sub-clinical but in some patients, cervical lymphadenopathy or ocular disease can be present. In most adults and children it does not cause serious illness, but it can cause blindness and mental retardation in congenitally infected children and devastating disease in immunocompromised individuals $[1,2]$.
There is report of precocious puberty as an endocrine manifestation in congenital toxoplasmosis [3].

Glucose-6-phosphate dehydrogenase (G-6-PD) deficiency, the most common enzyme deficiency worldwide, causes a spectrum of disease including neonatal hyperbilirubinemia, with acute and chronic hemolysis. Persons with this condition also may be asymptomatic. This X-linked inherited disorder most commonly affects persons of African, Asian, Mediterranean, or Middle-Eastern descent. Approximately 400 million people are affected worldwide $[4,5]$. 
Here is related a case of patient with acquired toxoplasmosis and glucose-6-phosphate dehydrogenase simultaneously.

\section{Case presentation}

A 5 years old male child, white race, natural of Minas Gerais State, Brazil, presented with fatigue, malaise and low-grade fever at least 10 days. Examination revealed: pallor, painless axillary and cervical lymphadenopathy and splenohepatomegaly. His hemogram showed leucocytosis with anemia $[\mathrm{Hb}=8.0 \mathrm{gm} \%$, WBC $=28,200$ cells $/$ cumm $(51 \%$ polymorphs and $49 \%$ lymphocytes)], his liver function tests were normal. At the thirteen day a clinical diagnosis of toxoplasmosis was considered, an enzyme-linked immunoassay (ELISA) for toxoplasma antigens in blood showed $\operatorname{IgM}=1: 256$ and $\operatorname{IgG}=1: 1024$. Ahead of the results the treatment with pyrimethamine $1 \mathrm{mg} / \mathrm{kg} / \mathrm{d}$ plus sulfadiazine $(100 \mathrm{mg} / \mathrm{kg} /$ day $)$, plus folinic acid was initiated.

In the seventh day of treatment the patient presented important jaundice and dark urine beyond decreased urine output, in the physical examination was observed, important splenohepatomegaly, tachycardia and tachypnea. A clinical diagnosis of acute hepatitis secondary to medications was considered. Laboratory exams showed: hemoglobin $6.4 \mathrm{gm} \%, \mathrm{WBC}=10,200$ cells $/ \mathrm{cumm}$, serum bilirubin $=1.4 \mathrm{mg} / \mathrm{dl}$ with indirect bilirubin $=0.9 \mathrm{mg} / \mathrm{dl}$, liver enzymes were normal, thus, a clinical diagnosis of acute hemolysis was considered and new examinations had shown reticulocyte count $=5.1 \%$ with corrected reticulocyte count $=1.7 \%$, direct coombs test and indirect coombs test being negative, urine routine examination showed was normal with absent bile salts and bile pigments and urine culture did not show any organism. A smear of the blood showed an important degree of hemolysis (Figure 1). The patient was screened for G-6-PD activity, which was absent.

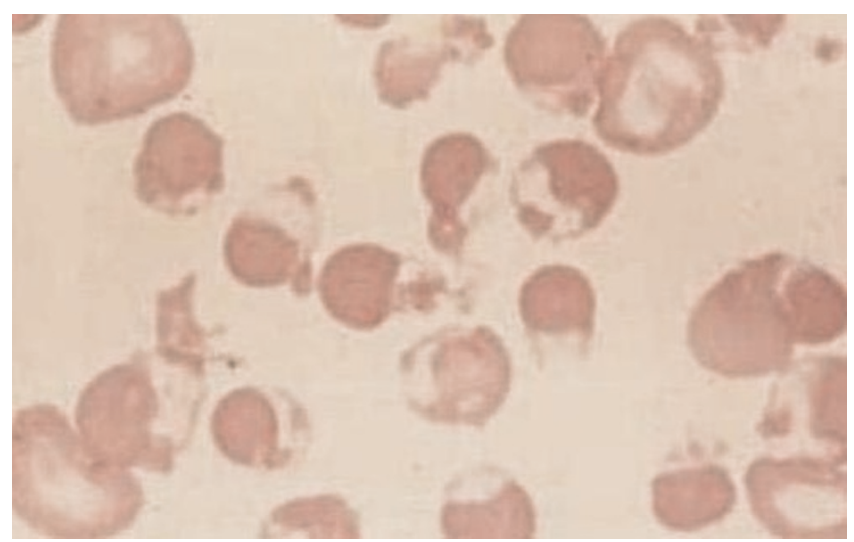

Figure I. Hemolysis due to G-6-PD deficiency in a child of five years old.
Thus a diagnosis of acute acquired toxoplasmosis with G-6-PD deficiency was considered with acute hemolysis due to sulfadiazine ingestion.

The sulfadiazine was discontinued and the treatment was changed for clindamycin so the patient was discharged without jaundice with hemoglobin $10.0 \mathrm{gm} \%$ and reticulocyte count $=0.5 \%$. On follow up after 1 month, his hemoglobin was $12.5 \mathrm{gm} \%$.

The parents of patient were advised to avoid antimalarials, sulfa drugs, chloramphenicol, nitrofurantoin, nalidixic acid, Vitamin $\mathrm{K}$ and others drugs due to his G-6-PD deficiency state.

\section{Discussion}

An unusual propensity for infection with catalase-positive organisms has been reported in patients with severe deficiency or complete absence of G-6-PD [4-6], however, propensity for infection with toxoplasma gondii was reported in only in a study [6] which showed an increased risk of toxoplasma infection by 2.5 folds in persons with G-6-PD deficiency as compared to G-6-PD normal individuals. The likely explanation for the increased infection rate is due to both direct destruction of the reticuloendothelial system by toxoplasma organisms and decreased killing effect of the phagocytic cells $[6,7]$.

In this case report the presence of the two diseases in a child, reinforce the findings of this propensity and alert us for such possibility, mainly considering the high prevalence of the two illnesses in the world. World-wide prevalence of toxoplasmosis varies of $2.3 \%$ to $93 \%$, while that the prevalence of G-6-PD deficiency varies of 0 to $27 \%$, so, ahead of the necessity of treatment for toxoplasmosis this fact must be taken in consideration, for the possibility of hemolysis secondary to sulfas.

Clinical presentations of G-6-PD deficiency are secondary at some factors such as infections, intake of fava beans, antimicrobial drugs, mainly sulfas and its derivatives. In the case above reported, the patient was using sulfadiazine for treatment of toxoplasmosis and developed acute hemolysis, at which quickly decreased after removed of the medicine and its exchange for clindamycin, at which is usually recommended for treatment of toxoplasmosis in specials situations [6-8].

\section{Abbreviations}

G-6-PD, Glucose-6-phosphate dehydrogenase; WBC, white blood cells.

\section{Consent}

Written informed consent was obtained from parents of the patient for publication of this case report and 
accompanying images. A copy of the written consent is available for review by the Editor-in-Chief of this journal.

\section{Competing interests}

The author declare that he have no competing interests.

\section{References}

I. Sukthana Y: Toxoplasmosis: beyond animals to humans. Trends Parasitology 2006, 22:137-I42.

2. Dubey JP: The history of toxoplasma gondii-the first 100 years. J Eukaryot Microbiol 2008, 55:467-475.

3. Setian N, Andrade RS, Kuperman H, Manna TD, Dichtchekenian V, Damiani $D$ : Precocious puberty: an endocrine manifestation in congenital toxoplasmosis. J Pediatr Endocrinol Metab 2002, I5: I 487-I 490.

4. Cappellini MD, Fiorelli G: Glucose-6-phosphate dehydrogenase deficiency. Lancet 2008, 37 I:64-74.

5. Frank JE: Diagnosis and Management of G6PD Deficiency. Am Fam Physician 2005, 72: I277-I 282.

6. Vives Corrons JL, Feliu E, Pudjades MA, Cardellach F, Rozman C, Carreras A, Jou JM, Vallespi MT, Zuazu FJ: Severe G6PD deficiency associated with chronic hemolytic anemia, granulocyte dysfunction and increased susceptibility to infection: description of a new molecular variant (G6PD Barcelona). Blood 1982, 59:482-434.

7. Tabbara KF, Sharara NA, Al-Momen AK: Toxoplasmosis in a group of glucose-6-phosphate dehydrogenase deficient patients. Saudi Med J 200I, 22:330-332.

8. Tenter AM, Heckeroth AR, Weiss LM: toxoplasma gondii: from animals to humans. Int J Parasitol 2000, 30:1217-1258.

\section{Do you have a case to share?}

Submit your case report today

- Rapid peer review

- Fast publication

- PubMed indexing

- Inclusion in Cases Database

\section{Any patient, any case, can teach us something}

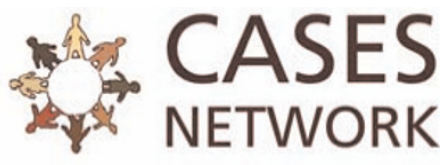

www.casesnetwork.com 